\title{
Effect of Monotherapy and Combination Therapy of Pantoprazole and Aprepitant in Gastric Esophageal Reflux Disease in Albino Rats
}

\author{
Kamleshwar Shukla, ${ }^{1}$ Prince Raj, ${ }^{1}$ Arun Kumar, ${ }^{1}$ Mukesh Kumar, ${ }^{2}$ and Gaurav Kaithwas ${ }^{1}$ \\ ${ }^{1}$ Department of Pharmaceutical Sciences, Babasaheb Bhimrao Ambedkar University, Vidya Vihar, Raebareli Road, \\ Lucknow 226 025, India \\ ${ }^{2}$ Department of Applied Animal Sciences, Babasaheb Bhimrao Ambedkar University, Vidya Vihar, Raebareli Road, \\ Lucknow 226 025, India \\ Correspondence should be addressed to Gaurav Kaithwas; gauravpharm@hotmail.com
}

Received 23 August 2013; Accepted 2 February 2014; Published 23 March 2014

Academic Editors: F. Maluf-Filho and C. Tosetti

Copyright (C) 2014 Kamleshwar Shukla et al. This is an open access article distributed under the Creative Commons Attribution License, which permits unrestricted use, distribution, and reproduction in any medium, provided the original work is properly cited.

\begin{abstract}
The present study was undertaken to elucidate the effect of pantoprazole and aprepitant on experimental esophagitis in albino rats. Groups of rats, fasted overnight, received normal saline $(3 \mathrm{~mL} / \mathrm{kg}$, sham control) or toxic control $(3 \mathrm{~mL} / \mathrm{kg})$ or pantoprazole $(30 \mathrm{mg} / \mathrm{kg})$ or aprepitant $(10 \mathrm{mg} / \mathrm{kg})$, or their combinations and were subjected to pylorus and forestomach ligation. Animals were sacrificed after $8 \mathrm{~h}$ and evaluated for the gastric $\mathrm{pH}$, volume of gastric juices, total acidity, esophagitis index, and free acidity. Esophageal tissues were further subjected to estimations of TBARS, GSH, catalase, and SOD. Treatment with pantoprazole and aprepitant significantly inhibited the gastric secretion, total acidity, and esophagitis index. The treatment also helped to restore the altered levels oxidative stress parameters to normal.
\end{abstract}

\section{Introduction}

Gastroesophageal reflux disease (GERD) is a gastrointestinal disorder and defined as a condition that develops due to reflux of stomach content into esophagus, causing troublesome symptoms or complications [1]. Heartburn is the most common symptom of GERD and is estimated to occur daily in seven percent of the US population [2]. In addition to heartburn, regurgitation and difficulty in swallowing are common GERD symptoms. GERD also includes subcategories of diagnosis: nonerosive esophageal reflux disease (NERD) and the other pathologies that result due to progression of GERD, including esophageal ulcer, esophageal stricture, Barrett's esophagus, and Barrett's carcinoma [1]. Several lines of treatments exist for the treatment and clinical management of GERD including proton pump inhibitors (PPIs) and $\mathrm{H}_{2}$ blockers. The clinical management of GERD is difficult and requires long-term therapy due to relapsing nature of disease. The clinical management by PPIs and $\mathrm{H}_{2}$ blockers is not very effective due to weak inhibitory activity in early phase and less effectiveness of the therapy within the initial hours of dosing [3]. From above it became obvious that GERD is a chronic disease and requires long-term symptomatic and pathological management [4].

Aprepitant is a selective high affinity antagonist of human substance P/neurokinin (NK1) receptor. Aprepitant has little or no affinity for serotonin (5-HT3), dopamine, and corticosteroid receptor and is used against chemotherapy-induced nausea and vomiting (CINV) and postoperative nausea and vomiting (PONV). In the antecedent studies aprepitant has demonstrated the inhibition of emesis induced by cytotoxic chemotherapeutic agents, such as cisplatin, via central action.

PPIs are used for the treatment of condition such as ulcer and Zollinger-Ellison syndrome that are caused by stomach acid [5]. Pantoprazole like other proton-pump inhibitors is the most potent gastric acid suppressants because of their ability to inhibit the proton pump $\mathrm{H}^{+}-\mathrm{K}^{+}$-ATPase, which is the final common pathway of gastric acid secretion and blocks the enzyme in the wall of the stomach that produces 
acid. It suppresses nocturnal and day time as well as foodstimulated gastric acid secretion by blocking the enzyme; the production of acid is decreased, and this allows the stomach and esophagus to heal [6].

In view of above, we hypothesize that aprepitant by virtue of its NK1 receptor blocking action (e.g., antiemetic action) and pantoprazole through proton pump inhibitor action will provide a long-term systemic relief in management of GERD. Henceforth, the present study has been undertaken with the objective to cut down the reflux and to decrease the production of gastric content using combination therapy of aprepitant and pantoprazole.

\section{Methods and Materials}

2.1. Drug and Chemicals. Aprepitant was received as a gift sample from Glanemark Pharmaceuticals Ltd. Mumbai, India, and pantoprazole was procured from the local market. All other chemicals were used of analytical grade.

2.2. Animals. Albino Wistar rats (120-150 gm) were obtained from the animal house of BBDNIIT, Lucknow. The albino rats were kept in polypropylene cage under standard condition of temperature $\left(37 \pm 1^{\circ} \mathrm{C}\right)$ with $12 \mathrm{~h}$ light: dark cycle with free access to a commercial pellet diet and water [7]. The experimental protocol was approved by Institutional Animal Ethics Committee (IAEC) of BBDNIIT, Lucknow (Ref. number BBDNIIT/IAEC/11/2012).

2.3. Induction of Esophagitis. Animals were randomized and divided into five groups of six animals each. Groups of rats, fasted overnight, received normal saline or control vehicle $(0.9 \% \mathrm{NaCl}$ in double distilled water), pantoprazole, aprepitant, or their combination as described in Table 2. After $1 \mathrm{~h}$, coeliotomy was performed and esophagitis was induced by ligating the forestomach and pylorus with 2-0 silk suture, under pentobarbitone anesthesia [8] (Figure 1).

After $8 \mathrm{~h}$ animals were sacrificed by cervical dislocation and the chest was opened with a median incision and the tissue esophagus and the stomach were removed. The stomach was opened along the greater curvature and the esophagus was dissected out by extending the dissection line along the major axis. The tissue was washed with normal saline and examined for lesion. The severity of the erosions was scored using Table 1 and the index was calculated by dividing the total score by ten, which was designated as esophagitis index [9]. The volume of gastric juice, total acidity, and $\mathrm{pH}$ was measured as described subsequently under "Gastric secretion in pylorus ligated rats" [10].

2.4. Scanning Electron Microscopy for Esophageal Tissue. Samples were fixed in $2.5 \%$ glutaraldehyde for $6 \mathrm{~h}$ at $4^{\circ} \mathrm{C}$ and washed in $0.1 \mathrm{M}$ phosphate buffer, for 3 changes each of $15 \mathrm{~min}$ at $4^{\circ} \mathrm{C}$. $1 \%$ osmium tetroxide was used as a postfixation for $2 \mathrm{~h}$ at $4^{\circ} \mathrm{C}$ and samples were washed in $0.1 \mathrm{M}$ phosphate buffer for 3 changes each of $15 \mathrm{~min}$ at $4^{\circ} \mathrm{C}$ to remove the uncreative fixative. Specimens were dehydrated by using increasing concentration of acetone, namely, 30\%, 50\%, 70\%,
TABLE 1: Scoring of erosion and severity.

\begin{tabular}{lcccc}
\hline Erosion $(\mathrm{mm})$ & 1 or less & $1-2$ & $2-3$ & $>3$ \\
\hline Score & 1 & 2 & 3 & 4 \\
\hline
\end{tabular}

$90 \%, 95 \%$, and $100 \%$ (dry acetone), to remove water at $4^{\circ} \mathrm{C}$ for 30 min period. After that, specimens were air-dried (critical point, i.e., 31.5 at $1100 \mathrm{psi}$ ). Specimens were mounted on to the aluminium stub with conductive paint or adhesive tape. Then specimens were observed in scanning electron microscope (JEOL-JSM-6490LV).

2.5. Statistical Analysis. All data were presented as mean \pm SD and analyzed by one-way ANOVA followed by Bonferroni test for the possible significance identification between the various groups. $P<0.05, P<0.01$, and $P<0.001$ were considered statistically significant. Statistical analysis was carried out using GraphPad software (3.2), San Diego, CA.

\section{Results}

Oral administration of aprepitant $(10 \mathrm{mg} / \mathrm{kg})$ significantly inhibited the esophagitis in the albino rats. Aprepitant significantly inhibited the esophagitis index (53.54\%), gastric volume (39.37\%), free acidity (33.69\%), and total acidity $(29.32 \%)$ in comparison with toxic control. Pantoprazole produced $80.64 \%$ inhibition of esophagitis index, respectively. The oral administration of aprepitant in combination of pantoprazole markedly decreased the gross volume of gastric juices (45.63\%), total acidity (40.45\%), free acidity $(16.22 \%)$, and esophagitis index $(62.58 \%)$ in comparison to toxic control (Table 2).

Tissue MDA level in the control and toxic control was found to be $0.81 \pm 0.08$ and $7.50 \pm 0.52$, respectively. There was significant decrease in the MDA level in the combination treatment in comparison to monotherapy and control as well. Blood GSH level in the normal control was found to be $208.60 \pm 3.83$ and in toxic control was $74.20 \pm 7.85$; similarly tissue catalase level in the control was found to be $24.49 \pm 2.19$ and in toxic control was $7.02 \pm 1.72$. There was significant increase in the blood GSH level and catalase level in the combination therapy in comparison to monotherapy. Tissue SOD level in the control was found to be $5.32 \pm 0.27$ and in toxic control was $0.89 \pm 0.073$. There was significant increase in the SOD level in the combination therapy in comparison to monotherapy (Table 3). The above results were also supported by the SEM photomicrograph (Figure 2).

\section{Discussion}

Ligating the forestomach and pylorus developed reflux esophagitis in all the animals marked by macroscopically visible necrosis and significant ulceration in the esophagus. Treatment with pantoprazole and aprepitant significantly inhibited the ulcer formation in esophagus. Treatment with aprepitant demonstrated significant protection against the 


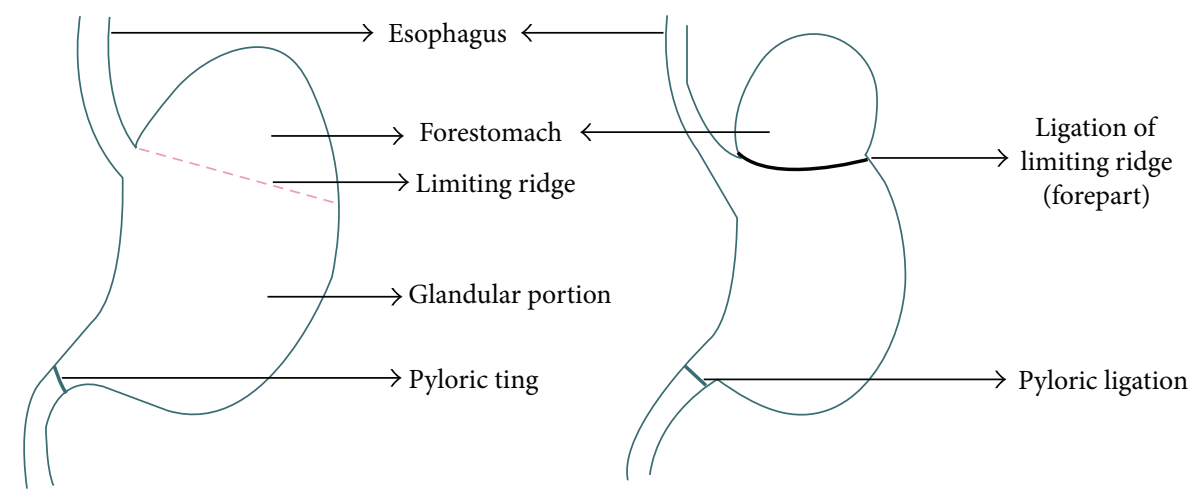

FIGURE 1: Schematic representation of pylorus and forestomach ligation.

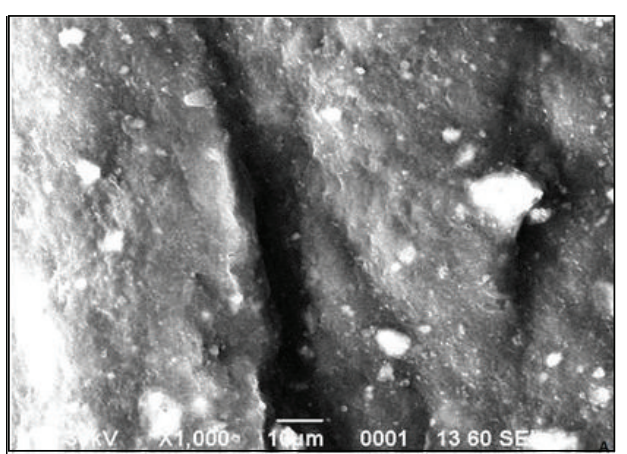

(a) Sham control

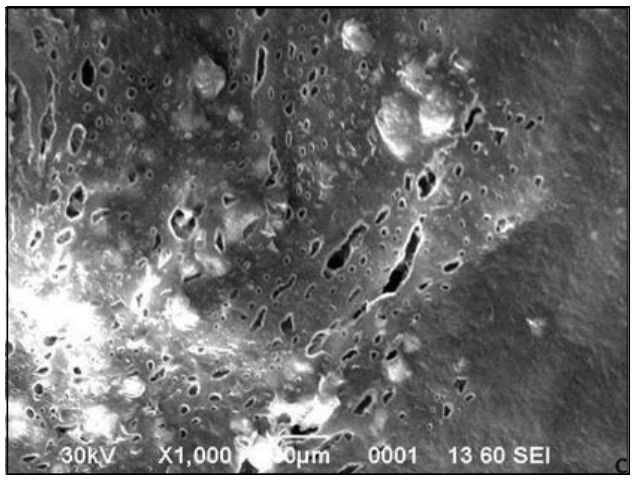

(c) Pantoprazole $(30 \mathrm{mg} / \mathrm{kg})$

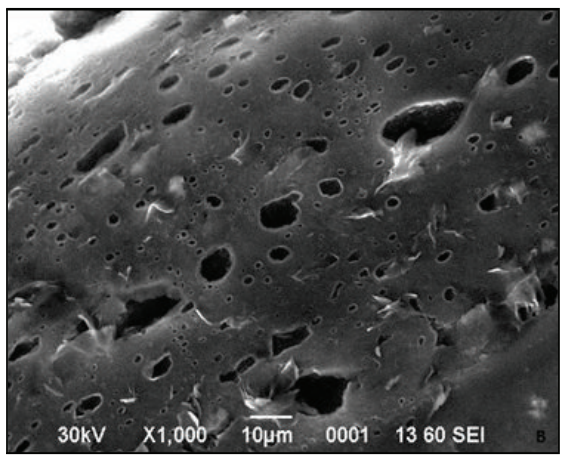

(b) Toxic control

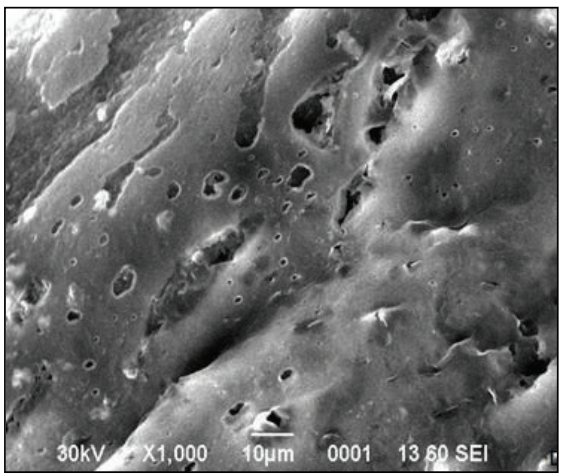

(d) Aprepitant $(10 \mathrm{mg} / \mathrm{kg})$

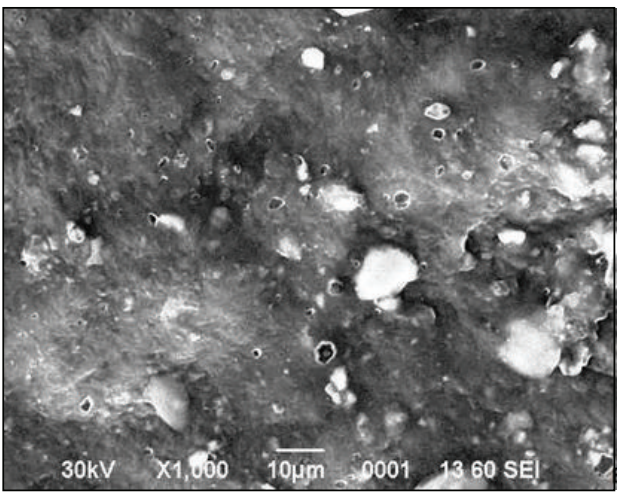

(e) Pantoprazole (30 mg/kg) + aprepitant $(10 \mathrm{mg} / \mathrm{kg})$

FIGURE 2: Scanning electron microscopic photomicrographs of the esophageal tissues. 


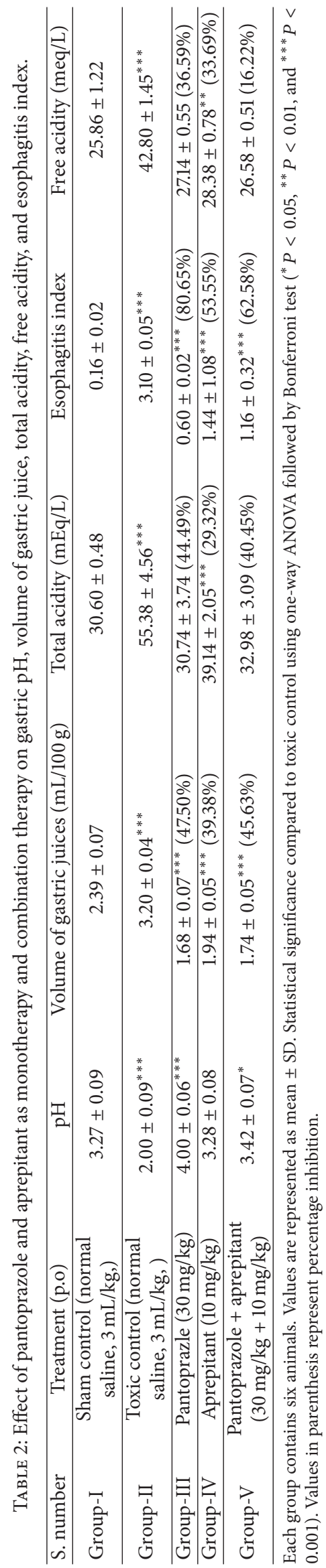




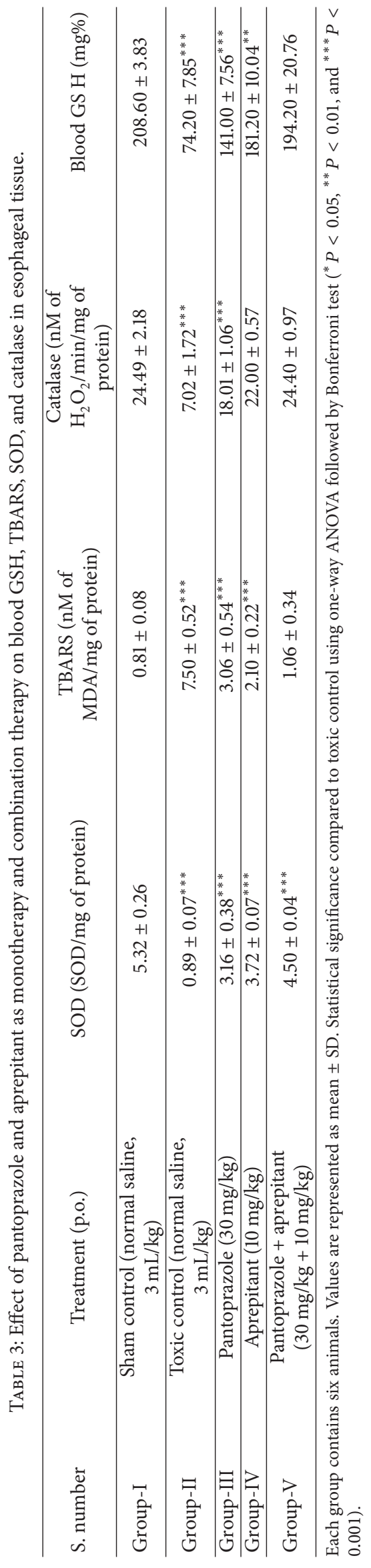


reflux esophagitis in the experimental animals. Aprepitant significantly reduced the esophagitis index, gastric volume, free acidity, and total acidity in comparison with toxic control. The beneficial effects of aprepitant observed in the present study could be attributed to its $\mathrm{NK}_{1}$ receptor antagonistic action providing antiemetic property to the aprepitant. The same has been attributed for its use in the management of chemotherapy induced nausea and vomiting [11]. The $\mathrm{NK}_{1}$ receptor blocking action of the aprepitant inhibits the reflux of acid into the esophagus and thereby provides a symptomatic relief in the present experiment.

Pantoprazole is a proton pump inhibitor having an $\mathrm{H}^{+} \mathrm{K}^{+}$ATPase and carbonic anhydrase inhibitory activity [12]. Pantoprazole is a well-established drug used for the treatment of peptic ulcer, which inhibits the secretion from the gastric cells and helps in providing relief in reflux disease and mucosal curing in gastric ulcers and GERD [13]. In the present experiment pantoprazole demonstrated reduction in gastric volume, total acidity, and esophagitis index and this observation is in concordance with the previous studies.

The combination of pantoprazole and aprepitant inhibited the esophagitis index, decreased the volume of gastric juices, and reduced the $\mathrm{pH}$ to a significant level, suggesting the possible synergistic effect. Thus the effect against GERD could be congregately attributed to the antisecretory action of pantoprazole and antiemetic action by aprepitant, and the same seems to accounts for decrease in gross volume of gastric juice secretion, total acidity, and esophagitis index in the present experiment as well.

Previous studies have elaborated the role of free radicals in pathogenesis of the reflux esophagitis in experimental animals [14]. Reflux esophagitis has been reported to increase malondialdehyde, a stable product of lipid peroxidation and a sensitive marker of membrane damage in esophageal tissues $[15,16]$. The oxidative stress leads to degradation of cellular membrane which produces MDA, which is a reactive substance and forms a color complex with the thiobarbituric acid. Significant increase in MDA in the toxic control suggests active participation of reactive oxygen species (ROS) and oxidative stress in GERD. This further enumerates that the ligation of pylorus and forestomach generates free radical species that attack lipid components, leading to lipid peroxidation. It is pertinent to mention that the concomitant administration of the pantoprazole and aprepitant as a monotherapy and combination therapy significantly inhibited the lipid peroxidation evidenced by decreased formation of MDA.

The glutathione (GSH) is a ubiquitous tripeptide, which is the most abundant low molecular weight thiol in almost all cells and is involved in a wide range of enzymatic reaction. A major function of GSH is to serve as a reductant in oxidation reduction processes, a function resulting in the formation of glutathione disulfide (GSSG). Free radical damage leads to consumption of GSH in the first few hours of oxidative stress, directing decreased GSH level, a marker of shortterm oxidative stress, and treatment with pantoprazole and aprepitant has significantly helped restore the same [17, 18]. Decrease in the levels of GSH represents its increased utilization by the cells due to oxidative stress and treatment with pantoprazole and aprepitant alone or in combination has significantly helped restore the levels of GSH; this effect could be attributed either due to increased oxidative stress or increased biogenesis of GSH. It would be worthwhile to mention that combination therapy of pantoprazole and aprepitant exhibited maximum antioxidant effect in comparison to monotherapy.

SOD is a free radical scavenging enzyme which neutralizes superoxide free radicals generated during the metabolism of drug; hence its concentration in the tissue decreases with increase in the time. SOD serves a key antioxidant role and decreases oxidative stress in the experimental animals; $\mathrm{SOD}$ scavenges the $\mathrm{H}_{2} \mathrm{O}_{2}$ to form water and molecular oxygen; the process involves the formation of hydroxyl and molecular oxygen free radical as the intermediate products [19]. The SOD in conjugation with catalase constitutes the major defense against free radicals. Catalase is a hemeprotein which catalyses the reduction of hydrogen peroxide (produced due to scavenging effect of SOD) and protect the tissue from highly reactive hydroxyl radical $[20,21]$. In the present experiment we observed simultaneous decrease in SOD and catalase activity after the ligation of pyloric end and forestomach. This decrease in SOD and catalase could be attributed to the increased oxidative stress and thereby increased utilization. Treatment with pantoprazole and aprepitant restored the diminished levels of SOD and catalase suggesting the decreased oxidative stress. It would be pertinent to mention that the combination therapy observed better antioxidant activity in comparison to monotherapy. The above observed findings are also supported by the finding from scanning electron microscopy.

It would be worthwhile to mention that no untoward effect was observed in animals treated with pantoprazole and aprepitant either alone or in combination. Our results suggest the possible therapeutic potential of combination therapy of pantoprazole and aprepitant against reflux esophagitis in experimental animals without any untoward effect. However, further studies are required to be undertaken to confirm its therapeutic potential against GERD.

\section{Abbreviations}

GERD: Gastroesophageal reflux disease

GSH: Glutathione

PPIs: Proton pump inhibitors

TBARS: Thiobarbituric acid reactive substance

MDA: Malondialdehyde

SOD: Superoxide dismutase.

\section{Conflict of Interests}

The authors declare that they have no conflict of interests regarding the publication of this paper.

\section{References}

[1] N. Vakil, S. V. Van Zanten, P. Kahrilas et al., "The Montreal definition and classification of gastroesophageal reflux disease: 
a global evidence-based consensus," American Journal of Gastroenterology, vol. 101, no. 8, pp. 1900-1943, 2006.

[2] P. J. Kahrilas, "Review article: gastro-oesophageal reflux disease as a functional gastrointestinal disorder," Alimentary Pharmacology and Therapeutics, Supplement, vol. 20, no. 7, pp. 50-55, 2004.

[3] S. Mitushing, J. Seok Jang, Y. Yoshizawa et al., "Proton pump inhibitor therapy before and after endoscopic submucosal dissection: a review," Diagnostic and Therapeutic Endoscopy, vol. 2012, Article ID 791873, 11 pages, 2012.

[4] E. Kuster, E. Ros, V. Toledo-Pimentel et al., "Predictive factors of the long term outcome in gastro-oesophageal reflux disease: six year follow up of 107 patients," Gut, vol. 35, no. 1, pp. 8-14, 1994.

[5] WeMeReC Bulletin, "Welsh medicines resource center," Canolfan Abnoddau Moddion Cymru, vol. 9, no. 2, 2002.

[6] K. M. Fock, N. Tally, R. Hunt, R. Fass et al., "Report of AsiaPacific consensus on the gastroesophageal reflux disease, treatment of gastroesophageal reflux disease clinical cornerstone 1 GERD 1," Journal of Gastroenterology and Hepatology, vol. 19, no. 4, pp. 357-367, 2004.

[7] S. K. Kulkarni, Handbook of Experimental Pharmacology, 2005.

[8] R. J. White, G. P. Morris, and W. G. Paterson, "Impairment of deglutition reflex by acid-induced esophageal mucosal injury," Digestive Diseases and Sciences, vol. 46, no. 4, pp. 802-807, 2001.

[9] R. Renu, G. Kaithwas, P. W. Ramtake, and S. A. Saraf, "Effect of Linum Usittatisumum fixed oil on experimental esophagitis in rats," Acta Gastroenterlogica Belgica, vol. 75, no. 3, pp. 331-335, 2012.

[10] G. Kaithwas and D. K. Majumdar, "Evaluation of antiulcer and antisecretory potential of L. us itatis imum fixed oil and possible mechanism of action," Inflammopharmacology, vol. 18, pp. 137145, 2010.

[11] R. M. Navari, "Management of chemotherapy-induced nausea and vomiting: focus on newer agents and new uses for older agents," Drugs, vol. 73, no. 3, pp. 249-262, 2013.

[12] H. P. Rang, M. M. Dale, J. M. Ritter, and R. J. F. Lower, Rang and Dale's P Harmacology, 6th edition, 2007.

[13] S. kunsch, A. Neesse, T. Linhart et al., "Prospective evaluation of duodenogastroesophageal reflux in gastroesophageal reflux disease patients refractory to proton pump inhibitor therapy digestion,” Digestion, vol. 86, no. 4, pp. 315-322, 2012.

[14] P. Khinchi, S. Saha, S. A. Saraf, and G. Kaithwas, "Combination therapy of gamma-aminobutyric acid derivative promotes proton pump inhibitors based healing of reflux esophagitis in animal model," Pharmacological Reports, 2014.

[15] S. Yusuf, A. J. Nok, D. A. Ameh, A. B. Adelaiye, and E. O. Balogun, "Quantitative changes in gastric mucosal glycoproteins: effect of cholinergic agonist and vagal nerve stimulation in the rat," Neurogastroenterology and Motility, vol. 16, no. 5, pp. 613619, 2004.

[16] A. Farhadi, J. Fields, A. Banan, and A. Keshavarzian, "Reactive oxygen species: are they involved in the pathogenesis of GERD, Barrett's esophagus, and the Latter's progression toward esophageal cancer?" American Journal of Gastroenterology, vol. 97, no. 1, pp. 22-26, 2002.

[17] H. J. Stein, R. A. Hinder, and M. M. J. Oosthuizen, "Gastric mucosal injury caused by hemorrhagic shock and reperfusion: protective role of the antioxidant glutathione," Surgery, vol. 108, no. 2, pp. 467-474, 1990.
[18] H. J. Stein, M. M. J. Oosthuizen, R. A. Hinder, H. Lamprechts, and P. O'Brien, "Effect of verapamil on hepatic ischemia/reperfusion injury," American Journal of Surgery, vol. 165, no. 1, pp. 96-100, 1993.

[19] W. Suwannaphet, A. Meeprom, S. Yibchok-Anun, and S. Adisakwattana, "Preventive effect of grape seed extract against highfructose diet-induced insulin resistance and oxidative stress in rats," Food and Chemical Toxicology, vol. 48, no. 7, pp. 1853-1857, 2010.

[20] G. Kaithwas, K. Dubey, and K. K. Pillai, "Effect of Aloe vera (Aloe barbadensis Miller) gel on doxorubicin-induced myocardial oxidative stress and calcium overload in albino rats," Indian Journal of Experimental Biology, vol. 49, no. 4, pp. 260268, 2011.

[21] G. Kaithwas and D. K. Majumdar, "In vitro antioxidant and in vivo antidiabetic, antihyperlipidemic activity o f linseed oil against streptozodocin- induced toxicity in albino rats," European Journal of Lipid Science and Technology, vol. 114, no. 11, pp. 1237-1245, 2012. 


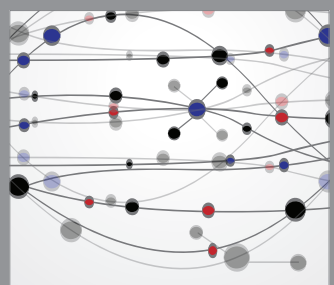

The Scientific World Journal
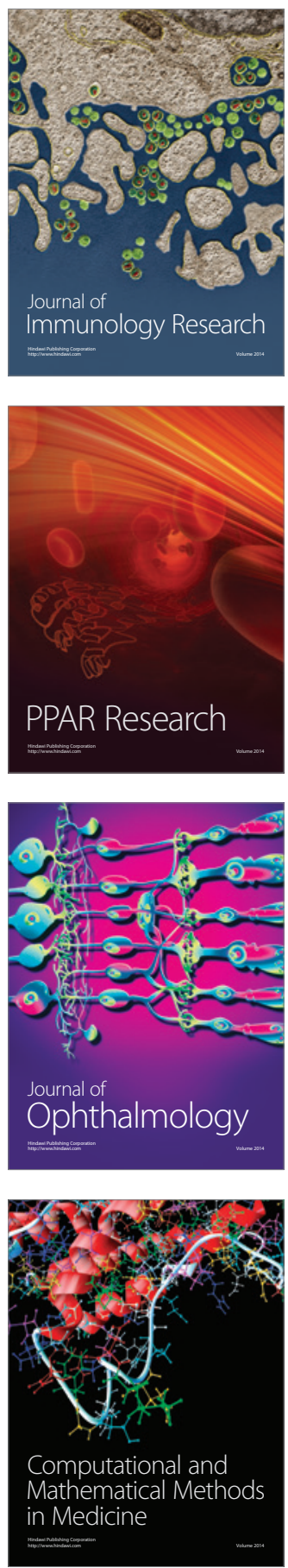

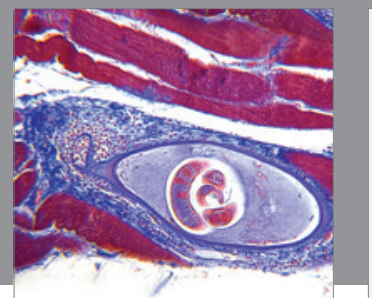

Gastroenterology

Research and Practice
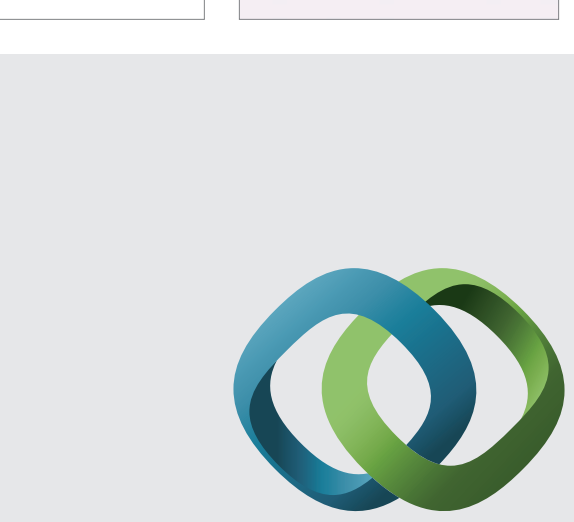

\section{Hindawi}

Submit your manuscripts at

http://www.hindawi.com
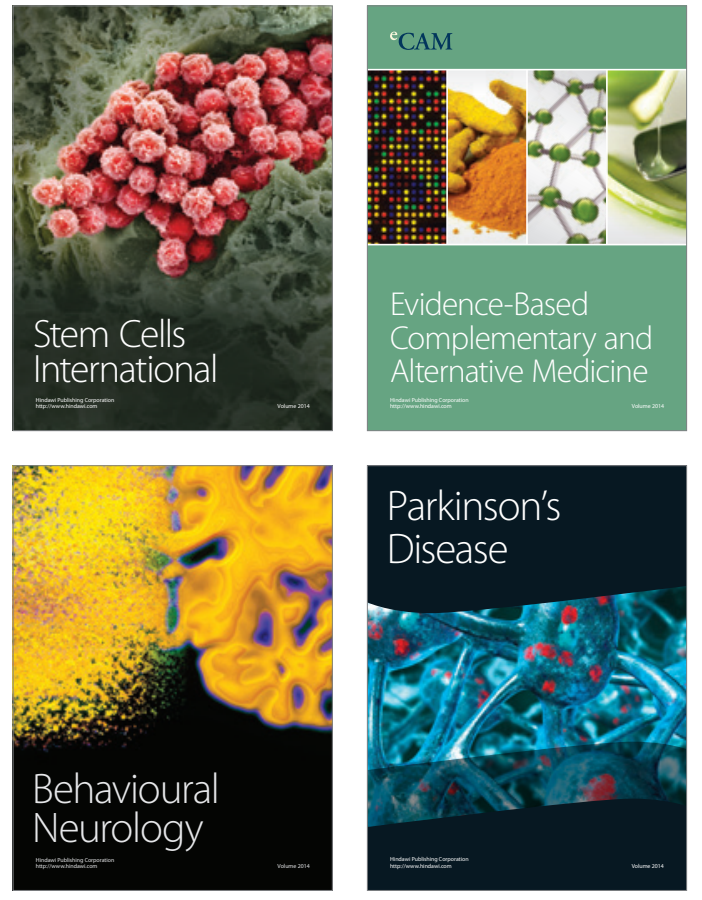
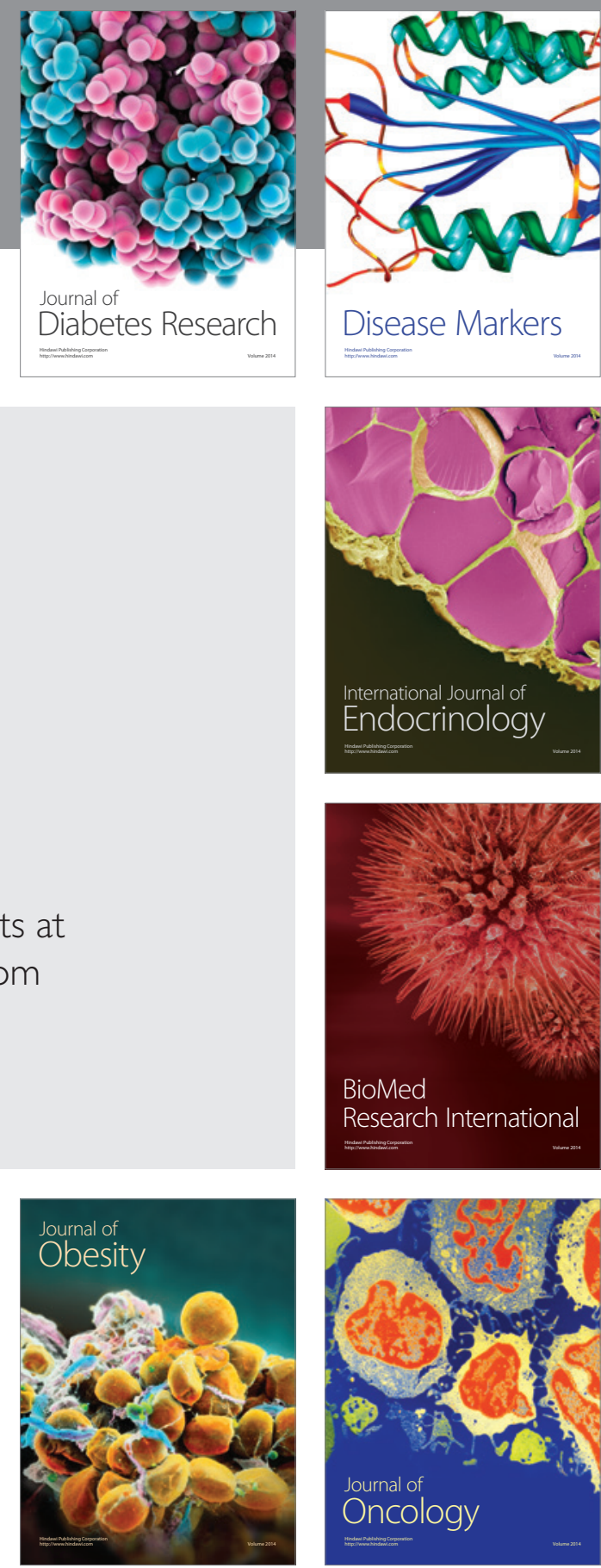

Disease Markers
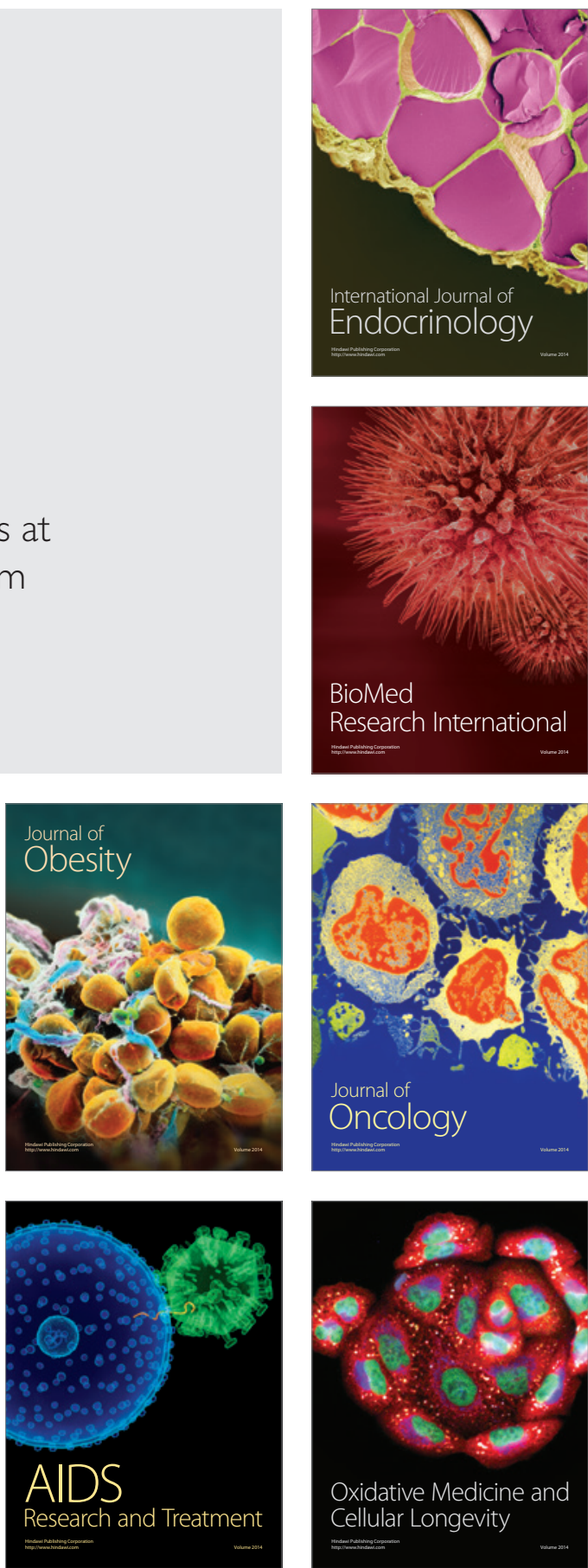